\title{
Accelerated rate of forgetting of spatial information following mammillary-body lesions in mice: Effects of context change on retention-test performance
}

\author{
ANTOINE N. TAKO, DANIEL J. BERACOCHEA, and ROBERT JAFFARD \\ Université de Bordeaux I, Bordeaux, France
}

\begin{abstract}
The experiments reported here examined the effects of radiofrequency lesions of the median mammillary nucleus (MM) in mice on spatial memory performance in a T-maze. The spontaneous alternation task used consisted of two forced trials (acquisition) followed, at varying retention intervals ranging from $5 \mathrm{~min}$ to $72 \mathrm{~h}$, by a free test trial (retention). Moreover, tests were conducted under different conditions by varying the intramaze context on the acquisition trials, the retention trial, or both. Thus, as compared with the usual condition of testing (OFF), animals were given trials with a change of intramaze context (cue added: $O N$ ). The first experiment conducted with retention intervals of $5 \mathrm{~min}$ and $6 \mathrm{~h}$ showed that MM-lesioned mice exhibited an accelerated rate of decay of spontaneous alternation when tested in normal conditions (OFF); however, changing the context (ON) on the acquisition, retention, or both acquisition and retention trials resulted in quite normal performance at the 6-h retention interval, as compared with that of controls. Since the most important effect of the context change was observed when it occurred on the retention test alone, this procedure was used in the second and third experiments in order to further analyze the phenomenon. These two experiments confirmed that when tested in the usual conditions, MM-lesioned mice reached chance level performance $(6 \mathrm{~h})$ more rapidly than controls $(48 \mathrm{~h}$ ), but that the between-group difference was totally alleviated when both groups were provided with the context change on the retention test. Moreover, whatever the retention interval (from 6 to $72 \mathrm{~h}$ ), this context change had no significant effect on the performance of control animals. These results suggest that MM lesions induce an accelerated rate of "forgetting" for spatial information, which is more likely due to an impairment of retrieval processes than to either an encoding deficit or a faster decay of the memory trace. In these conditions, the context change is supposed to stimulate searching operations, thus leading to normal remembering.
\end{abstract}

Patients with alcoholic Korsakoff's disease have frequently been reported to exhibit a profound anterograde amnesia which has mainly been associated with diencephalic pathology. The conclusion that this diencephalic amnesia is the consequence of damage to the mammillary bodies (Brierly, 1977) has been challenged by the proposal that medial thalamic lesions alone may be sufficient to induce the amnesic syndrome (McEntee, Biber, Perl, \& Benson, 1976; Victor, Adams, \& Collins, 1971). Moreover, since neuropathological evidence from alcoholic patients has also implicated diffuse brain damage (Victor et al., 1971), attempts to relate memory deficits to damage to specific structures have used animal models. These experiments have shown that circumscribed lesions

The research presented here was supported by Centre National de la Recherche Scientifique (U.A. 339). The work constituted a portion of the doctoral dissertation of A. N. Tako, whose present address is Département de Biologie et Physiologie Animale, Faculté des Sciences d'Abidjan, 04 BP 322, Abidjan, Côte d'Ivoire, France. We thank Tom Durkin for his helpful comments on the manuscript. Correspondence and requests for reprints may be sent to R. Jaffard, Laboratoire de Psychophysiologie, UER de Biologie, Université de Bordeaux I, Avenue des Facultés, 33405 Talence Cedex, France. of the mammillary body (MM) do indeed produce learning and memory impairments (Aggleton \& Mishkin, 1985; Greene \& Naranjo, 1986; Holmes, Butters, Jacobson, \& Stein, 1983; Holmes, Jacobson, Stein, \& Butters, 1983; Holmes \& Schroeder, 1986; Irle \& Markowitsch, 1982; Saunders, 1983; Thompson, 1981). However, as pointed out by Aggleton and Mishkin (1985), there is accumulated experimental evidence that if MM lesions produce severe impairment in a variety of spatial tasks, they leave performance on nonspatial tasks quite unaffected.

In previous experiments from our laboratory, we found that prolonged (6-7 months) ethanol consumption in mice of the BALB/c strain resulted in spatial memory deficits (Beracochea \& Jaffard, 1985), which were associated with pronounced neuronal loss in the median mammillary nucleus (Lescaudron, Beracochea, Verna, \& Jaffard, 1984). However, further examination of the brains of alcohol-treated mice revealed that other structures generally considered to play a key role in memory processes (i.e., hippocampus, anterior and mediodorsal thalamic nuclei, and nucleus basalis magnocellularis) also exhibited neuronal losses (see Beracochea, Lescaudron, Verna, \& Jaffard, 1987; Lescaudron \& Verna, 1985); even though 
these structures were much less damaged than the MM, their contribution to the observed memory deficits could not be ruled out. Consequently, the first purpose of the present study was to determine whether an experimental (electrolytic) lesion of the MM alone would induce the same deficits as those observed after prolonged ethanol treatment. Such ethanol treatment for 6-7 months was found to induce an accelerated rate of decay of spontaneous alternation as a function of the interval between two forced trials (acquisition) and a free test trial (retention) in a T-maze. Experimental subjects reached chance levels of performance at intervals of between $1 \mathrm{~h}$ and $6 \mathrm{~h}$, as compared with more than $24 \mathrm{~h}$ for controls (Beracochea, Durkin, \& Jaffard, 1986; Beracochea \& Jaffard, 1985). Subsequent analysis showed that alcohol-treated mice suffered from an increased vulnerability to proactive interference (Beracochea \& Jaffard, 1985). Since animals were repeatedly tested in the same apparatus, it was hypothesized that a part of their deficit (i.e., accelerated rate of forgetting) might result from the use of highly familiar material, which could lead to impaired accuracy in discriminating the most recent events (the last twice-visited arm) from previous ones. Since it seemed possible that MM lesions could lead to the same consequences, we sought to determine, in our first experiment, whether providing the animal with a different intramaze context on one particular test (i.e., acquisition + retention trials) would improve its performance. Indeed, performance of amnesics has been shown to improve when response competition was reduced by providing extrinsic cues that would constrain the class of items or events from which the subject had to choose a response (Winocur \& Kinsbourne, 1978; Winocur, Kinsbourne, \& Moscovitch, 1981). As will be seen in our first experiment, such a procedure did facilitate performance in MM-lesioned subjects, but probably not because they associated the to-beremembered information with a different context; indeed, changing the context at the time of retrieval (retention) alone was found to be equally efficient as, if not more efficient than, a change that occurs either on acquisition alone or on both acquisition and retention trials.

\section{EXPERIMENT 1}

The aim of the first experiment was to determine whether MM lesions would induce an accelerated rate of decay of spontaneous alternation as a function of time (retention interval). Pilot studies from our group had shown that kainic acid lesions of the MM did induce such a deficit. Using two forced (acquisition) trials followed by a free (test) trial, MM-lesioned subjects showed chance levels of performance for a 6-h retention interval, whereas control mice still significantly alternated at $24 \mathrm{~h}$. The second aim of the experiment was to determine whether this deficit was reduced on tests in which a different intramaze context was provided. More precisely, since the abovementioned deficit could be explained by familiarity (see the introduction), mice were given some tests with a new context on both acquisition and retention (ON-ON), on acquisition alone (ON-OFF), or on retention alone (OFF-ON).

\section{Method}

\section{Subjects}

The subjects were 30 experimentally naive male mice of the BALB/c strain. The mice were approximately 14-16 weeks of age at the beginning of the experiment and weighed approximately $28 \mathrm{~g}$. The mice were housed individually with ad-lib access to food and water in a constant-temperature room $\left(23^{\circ} \pm 1^{\circ} \mathrm{C}\right)$ maintained on a 12:12 light-dark cycle (7:00 a.m. on).

\section{Apparatus}

All testing was done in a T-maze constructed of gray Plexiglas. Stem and arms were $35 \mathrm{~cm}$ long, $10 \mathrm{~cm}$ wide, and $25 \mathrm{~cm}$ high. The startbox $(10 \times 12 \mathrm{~cm})$ was separated from the stem by a vertical sliding door. Horizontal sliding doors were placed at the entrance to each arm. Ilumination inside the apparatus (about $50 \mathrm{~lx}$ ) was provided by a lamp positioned $2 \mathrm{~m}$ above the stem.

\section{Procedure}

Preoperative testing. Testing was conducted between 9 a.m. and 5 p.m. Before surgery, all animals were given two free-exploration sessions of $5 \mathrm{~min}$ each in the apparatus in order to familiarize them with the conditions they would encounter in the alternation tests. Then each mouse was submitted daily to a session of six successive trials over 3 consecutive days. To begin a trial, the mouse was placed in the startbox; after $30 \mathrm{sec}$, the door to the stem was opened. When the mouse entered one of the arms, the door to that arm was closed. The chosen arm and the time that elapsed between when the door to the stem was opened and when the door to the arm was closed (running latency) were noted. After a 30-sec confinement in the chosen arm, the mouse was removed and placed in the startbox for the following trial, which began with a 30-sec confinement. Visible traces of urine and feces were removed from the stem and arms between trials.

Following completion of this testing, the mice were submitted daily, for 4 consecutive days, to an alternation test with the forcedtrial procedure used after surgery. In this procedure, the subjects were forced twice to enter one of the arms, access to the other being blocked by the sliding door. Thus, two forced trials separated by a 30-sec interval were given as acquisition trials in order to enhance acquisition; this was followed by one test trial given 5 min later.

Individual preoperative rates of spontaneous alternation in the free-trial procedure (six trial sessions) were used to counterbalance the assignment of subjects to each group.

Postoperative testing. Following surgery, the animals were allowed 1 week for recovery. The experimenter did not know to which group an animal belonged.

Postoperative testing began with two free-exploration sessions of $5 \mathrm{~min}$ each. Then each animal was submitted, either daily or every $48 \mathrm{~h}$, to a test consisting of two forced acquisition trials followed by a free test trial given either $5 \mathrm{~min}$ or $6 \mathrm{~h}$ later. It is important to note that after the free trial had been completed, the animal was allowed to freely explore the maze for 5-6 min; this procedure was used to reinforce the familiarity of the normal intramaze context, so that, whatever the conditions encountered in the immediately preceding test (cardboard or not, see below), this exploration session was conducted without the cardboard. Thus, during the course of testing, the time duration during which the animals were exposed to the cardboard was about 10 times less than their exposure to the normal condition. For the 6-h retention interval, each subject was tested several times in each of the following four 
conditions. In Condition B (four tests), the intramaze context was changed on both the acquisition and test trials by placement of a white cardboard $(12 \times 19 \mathrm{~cm})$ between the two arms against the wall perpendicular to the stem (ON-ON). In Condition $\mathrm{C}$ (four tests), the same cardboard was in place on the acquisition trials but not on the test trial (ON-OFF), and vice versa for Condition $D$ (four tests; OFF-ON). Results obtained in these three experimental conditions were compared with those recorded in Condition A (eight tests) which was the normal (or reference) condition, in which the cardboard was not used (OFF-OFF); testing at the 5-min retention interval (four tests) was conducted only under Condition A.

In each of these conditions, the direction in which a given subject was forced to go on acquisition alternated on consecutive tests, so that turn biases could be eliminated (chance level: $50 \%$ ).

Finally, the sequence in which successive conditions were used was as follows: A, $5 \mathrm{~min}, \mathrm{~B}, \mathrm{~A}, \mathrm{C}, \mathrm{D}, 5 \mathrm{~min}, \mathrm{~A}, \mathrm{D}, \mathrm{A}, \mathrm{C}$ and $\mathrm{B}$, with each animal being tested twice at each step of the sequence.

\section{Surgery}

Animals were anesthetized with sodium pentobarbital $(100 \mathrm{mg} / \mathrm{kg})$ and were positioned in a stereotaxic apparatus. A trephine hole was drilled midline at $2.5 \mathrm{~mm}$ posterior to the bregma, and the electrode was inserted to a depth of $5.5 \mathrm{~mm}$ below the skull. Radiofrequency lesions were produced by passing anodal high-frequency $(500 \mathrm{kHz})$ current $(120 \mathrm{~mA}$ for $15 \mathrm{sec})$ through the depth electrode and an alligator clip attached to the animal's paw. Sham-lesioned mice underwent exactly the same surgical procedure, except that no current was passed.

\section{Histology}

At the end of the experiments, the animals were sacrificed; their brains were removed and fixed in $10 \%$ formaldehyde. Frozen coronal sections, $40 \mu \mathrm{m}$ thick, were mounted on slides and stained with thionine. Under microscopic examination, the area of the lesion was checked and drawn on frontal sections.

\section{Data Analysis}

Mixed-design and separate analyses of variance (ANOVAs) were performed with retention interval and context change/no change as the within-groups factors and lesion/no lesion as the between-groups factor.

\section{Results}

Since no differences were observed between shamlesioned and unoperated animals (ANOVA, $F<0.40$ ), the data from these two groups were pooled for analysis (control group, C, $n=14$ ). Six experimental animals with either misplaced lesions $(n=5)$ or no apparent lesion $(n=1)$ were discarded from the final behavioral analysis (see Experiment 2). Results are summarized in Figure 1. In normal conditions (OFF-OFF), experimental subjects $(n=10)$ exhibited a significantly greater decline in spontaneous alternation rates than did controls between the 5 -min and 6-h retention intervals $[F(1,22)=27.0, p<$ $.001]$. Although no differences were observed for the shortest $(5 \mathrm{~min})$ interval $(\mathrm{C}=82.1 \%, \mathrm{MM}=81.7 \%)$, MM-lesioned mice were markedly impaired at the longer (6 h) interval [51.2 \pm 2.9 for $\mathrm{MM}$ mice vs. $75.9 \pm 3.1 \%$ for controls; $F(1,22)=31.5, p<.001]$. For this 6 -h interval, changing the context on acquisition (ON-OFF), retention (OFF-ON), or both (ON-ON), significantly improved performance [context effect, $F(3,66)=4.71, p=$ $.005]$; this phenomenon was much more pronounced in the $M M$ than in the control group [context $\times$ group interaction, $F(3,66)=3.81, p=.013$ ]. Thus, the mean rate of spontaneous alternation was significantly increased in $\mathrm{MM}$ animals $[51.3 \%$ to $75.8 \% ; F(3,27)=6.39, p=$

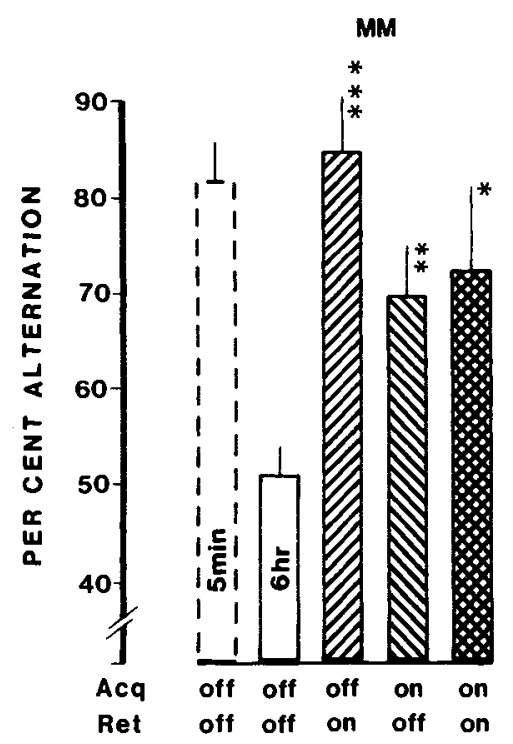

Controls

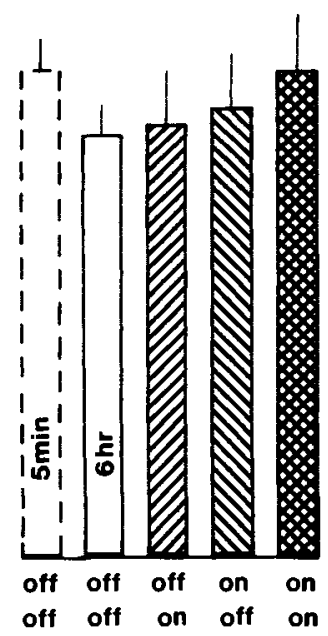

Figure 1. Percent spontaneous alternation (mean $\pm S E M$ ) in MM-lesioned (left) and control (right) mice as a function of the retention interval ( $5 \mathrm{~min}$ and $6 \mathrm{~h}$ ) in normal conditions of testing (OFF-OFF) (white columns) and for the 6-h interval with varying intramaze contextual cues (left to right: cardboard added [ON] on retention, on acquisition, and on both acquisition and retention; hatched columns). Significantly different from the 6-h OFF-OFF condition: ${ }^{* * *} p<.001,{ }^{* *} p<.01,{ }^{*} p<.05$. 
$.002]$, but no significant effect was observed in control animals (75.9\% to $79.2 \%$ ). Finally, as shown in Figure 1, for MM-lesioned animals, the OFF-ON procedure seemed to be slightly more efficient than the ON-OFF or $\mathrm{ON}-\mathrm{ON}$ procedures; however, only the difference between the OFF-ON and ON-OFF procedures (respectively, $85.0 \% \pm 5.5 \%$ and $70.0 \% \pm 5.0 \%$ ) approached the statistical level of significance $[F(1,9)=3.86, p=.078]$.

Running latencies were very variable among subjects, but did not differ significantly among groups. As shown in Table 1, a slight increase in latencies was observed both on the first forced trials (acquisition), relative to the free choice trials (retention), and with the cardboard (ON) relative to without (OFF). No between-group differences were observed for the second forced trial (acquisition; not shown in Table 1).

\section{Discussion}

The present data indicate that MM-lesioned mice, like alcohol-treated mice (Beracochea \& Jaffard, 1985), exhibit an accelerated rate of spontaneous-alternation decay as a function of the time interval between two forced acquisition trials and a free trial used as a retention test. The fact that levels of spontaneous alternation were nor$\mathrm{mal}$ for the shortest $(5 \mathrm{~min})$ interval indicates that MM lesions do not disrupt the animals' "motivation"' to alternate. The same conclusion can be drawn from previous experiments that have shown that MM lesions do not disrupt spontaneous alternation either on two successive free trials separated by a 30 -sec interval (discrete trial procedure) or on a sequential test procedure that uses a 5-sec intertrial interval (Beracochea \& Jaffard, 1987). Consequently, we suggest that the deficit presently observed for the 6-h retention interval results from what can be operationally defined as an accelerated rate of forgetting. However, when the MM-lesioned animals were provided with an unusual intramaze context on a particular test, performance dramatically improved. Although all three conditions had a significant facilitative effect, the scores for the OFF-ON condition (cardboard added on the retention trial only) were unexpectedly higher numerically, though not significantly, than those for the two other conditions. This suggests that MM-lesioned mice suffer mainly, if not exclusively, from a retrieval deficit that can be alleviated by providing the animal with a context change. In contrast, this facilitative effect was not observed in control subjects. However, since, for the 6-h interval, these animals still exhibited a high level of performance in normal conditions of testing, this could have resulted from a ceiling effect.

\section{EXPERIMENT 2}

The purpose of Experiment 2 was to determine whether the facilitative effect observed at the 6-h interval in MMlesioned mice when the context was changed at the time of retention (OFF-ON condition) could also be shown at longer intervals ( 24 and $48 \mathrm{~h}$ ). Moreover, since the ceiling effect was one of the plausible explanations for the lack of facilitation in normal mice, it was necessary to test the animals at retention intervals at which their performance approached chance levels. Finally, such a comparison seemed particularly interesting in view of suggestions that amnesics reach states of memory that are not qualitatively different from those attained by normal subjects much more quickly than do normal subjects (Mayes \& Meudell, 1984). In these conditions, one could expect that the context change would be as efficient in controls as in MM-lesioned subjects for retention intervals leading to chance-level performance.

\section{Method}

\section{Subjects}

A total of 45 experimentally naive male mice of the BALB/c strain were used in this experiment. Age and housing were as described in Experiment 1.

\section{Apparatus and Procedure}

The preoperative testing procedure was the same as described in Experiment 1. Postoperative testing was conducted as described in-Experiment 1, except that three retention intervals were used-

Table 1

Median Running Latencies (ec) and Interquartile Range for the First Forced Trial and the Subsequent Choice Trial (Retention Interval: $6 \mathrm{~h}$ )

\begin{tabular}{|c|c|c|c|c|c|c|c|c|}
\hline \multirow[b]{3}{*}{ Condition } & \multicolumn{4}{|c|}{ Group MM } & \multicolumn{4}{|c|}{ Group C } \\
\hline & \multicolumn{2}{|c|}{ Acquisition } & \multicolumn{2}{|c|}{ Retention } & \multicolumn{2}{|c|}{ Acquisition } & \multicolumn{2}{|c|}{ Retention } \\
\hline & Latency & Range & Latency & Range & Latency & Range & Latency & Range \\
\hline OFF & 29 & $8-84$ & & & 25 & $10-77$ & & \\
\hline OFF & & & 20 & $6-78$ & & & 24 & $7-68$ \\
\hline OFF & 27 & $7-65$ & & & 26 & $12-72$ & & \\
\hline ON & & & 29 & $11-110$ & & & 27 & $8-67$ \\
\hline ON & 43 & $13-94$ & & & 36 & $17-121$ & & \\
\hline OFF & & & 19 & $9-74$ & & & 22 & $7-72$ \\
\hline ON & 35 & $9-108$ & & & 29 & 14-99 & & \\
\hline ON & & & 27 & $8-82$ & & & 25 & $6-70$ \\
\hline
\end{tabular}

Note- $\mathrm{MM}=$ mammillary-body lesioned, $\mathrm{C}=$ controls, $\mathrm{ON}=$ cardboard added, $\mathrm{OFF}=$ no cardboard (see Figure 1). 


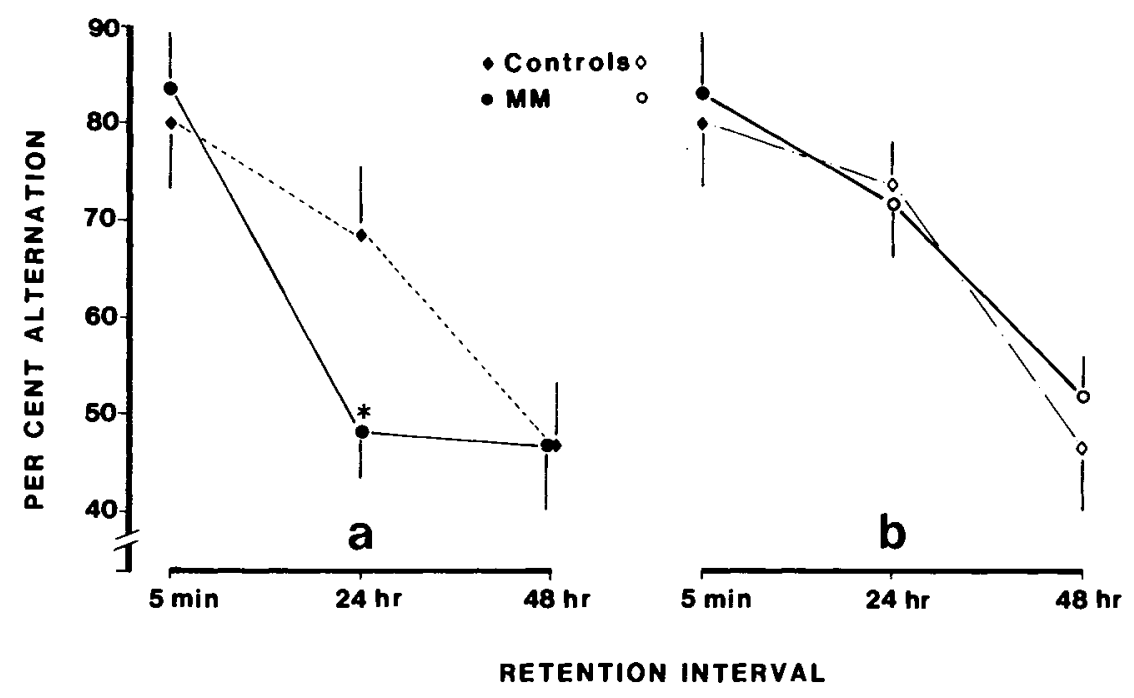

Figure 2. Percent alternation (mean $\pm S E M$ ) as a function of the retention interval in MMlesioned and control groups: (a) in normal conditions of testing (OFF-OFF), and (b) with a context change between acquisition (OFF) and retention (ON; cardboard added) (open symbols). *Significantly different from the control group, $p=.024$.

$5 \mathrm{~min}, 24 \mathrm{~h}$, and $48 \mathrm{~h}$-and, for the two longer intervals, two experimental conditions were used-A $=$ OFF-OFF (normal condition) and $\mathrm{C}=\mathrm{OFF}-\mathrm{ON}$ (cardboard added on the retention test trial). Tests at the 5-min retention interval (Condition A) were given at the beginning (two tests) and at the end (two tests) of the test series. Moreover, within each group, animals were assigned randomly to four subgroups according to the order in which they would encounter the four experimental conditions (i.e., $24 \mathrm{~h}, \mathrm{~A} ; 24 \mathrm{~h}, \mathrm{~B}$; $48 \mathrm{~h}, \mathrm{~A}$; and $48 \mathrm{~h}, \mathrm{~B}$ ); each animal was tested four times in each condition. Data analysis was performed as in Experiment 1.

\section{Surgery}

The 45 animals were assigned to three groups according to their performance on preoperative testing (see Experiment 1): MMlesioned $(n=20)$, sham-lesioned $(n=8)$, and unoperated controls $(n=7)$. Surgery was conducted as described in Experiment 1.

\section{Results}

\section{Behavior}

Since no differences were observed between shamlesioned and unoperated animals (ANOVA, $F<0.68$ ), the data from these two groups were pooled for analysis (control group, $n=15$ ). Five experimental animals with misplaced lesions were discarded from the final behavioral analysis. The results are summarized in Figure $2 \mathrm{a}$. In normal conditions (OFF-OFF; Figure 2a), between $5 \mathrm{~min}$ and $24 \mathrm{~h}$, experimental subjects $(n=15)$ exhibited a higher rate of decrease of spontaneous alternation than did controls $[F(1,28)=3.87, p=.056]$. Thus, although no differences were observed for the shortest $(5 \mathrm{~min})$ interval $(C=80.0 \% ; M M=83.3 \%)$, MM-lesioned mice were impaired at the $24-\mathrm{h}$ interval $[48.3 \%$ vs. $68.3 \%$; $F(1,28)=5.63, p=.023$ ]. With the 48-h interval, both groups performed at chance (46.7\% in both cases).

A comparison between performances recorded without (OFF-OFF) and with (OFF-ON) the cardboard added on the retention test trial ( 24 and $48 \mathrm{~h}$ ) showed that, in the latter condition, performance was significantly improved [context effect: $F(1,28)=4.44, p=.042$ ]. As shown in Figure $2 b$, the facilitative effect was observed only at the 24-h interval for MM-lesioned subjects [from $48.3 \%$ to $71.7 \% ; F(1,14)=9.66, p=.007]$. For control mice, changing the context on either the $24-\mathrm{h}$ or the 48 -h retention intervals had no effect $[F(1,14)=0.22]$. Finally, the between-groups difference that had been observed under normal conditions (OFF-OFF, Figure 2a) was completely alleviated when both groups were tested with the OFF-ON procedure [Figure $2 \mathrm{~b}$; MM vs. C for the $24-\mathrm{h}$ and $48-\mathrm{h}$ retention intervals: $F(1,28)=0.08$ ].

\section{Histology}

Figure 3 schematically depicts the area of brain damage in mice with $\mathrm{MM}$ lesions. We estimated that the damaged area of the MM was between $30 \%$ and $75 \%$. Animals with smaller and generally more ventral lesions (less than $15 \%-20 \%$ of the nucleus) were discarded from the analysis. The posterior, superior, and lateral MM were slightly damaged in several cases, but there was no lesion of nucleus interpeduncularis in the animals used for behavioral analysis.

\section{Discussion}

The present data confirm (for a longer interval-24 h) the facilitative effect, for MM-lesioned mice, of a context change (cardboard added) that occurs at the time of the retention test. This context change was ineffective at the 48-h interval. For control subjects, context change had no effect on performance, whatever the retention interval ( 24 or $48 \mathrm{~h}$ ). This suggests that the lack of effect observed in Experiment 1 cannot be explained by a ceiling effect, 


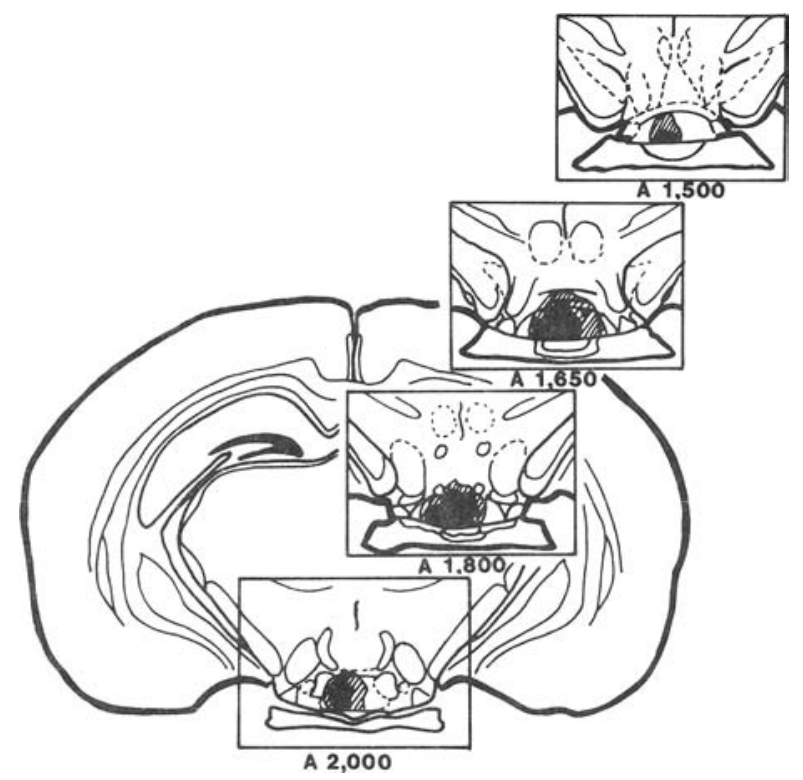

Figure 3. Representative (dark area) and maximal (dashed area) extent of the lesions in mammillary bodies (reconstructions are made on plates of the Lehmann, 1974, atlas of mice).

since, for the 48-h interval, the animals displayed chance levels of alternation. It seems likely that the facilitative effect of the context change in experimental subjects depends closely on the degree of novelty of the new context relative to the familiar context. Previous experiments conducted on MM-lesioned mice tested for spontaneous alternation in a sequential test procedure have shown that the facilitative effect of the context change (cardboard added: $O N$ ) rapidly dissipates, if this new context is maintained over subsequent trials, and transiently reappears as soon as the initial (familiar: OFF) context is reinstated (Beracochea \& Jaffard, 1987). Although these observations clearly show that MM-lesioned mice rapidly habituate to a given context, one cannot exclude the possibility that their rate of habituation is impaired relative to that of controls. More precisely, the hypothesis that the differential effect of context change in MM mice as compared with that of normal mice results from the controls' more rapid habituation to the ON condition cannot be ruled out. Although the findings of a careful examination of individual performance as testing progressed (Experiments 1 and 2) did not appear to support such a proposal, the following experiment was designed to investigate this possibility.

\section{EXPERIMENT 3}

The aim of this experiment was to determine whether the lack of effect of context change in normal mice would result from rapid habituation to the unusual $(O N)$ intramaze context. Accordingly, exposures to the ON condition were reduced to a minimum, and exposures to the normal condition (OFF) were increased.

\section{Method}

\section{Subjects}

Thirty-nine experimentally naive male mice of the BALB/c strain were used in the experiment. Age and housing were as described in Experiment 1.

\section{Apparatus and Procedure}

The basic procedure was as described in Experiment 1, except that, with the forced-trial procedure, no internuption occurred between the preparation phase (identical to preoperative testing in Experiments 1 and 2) and the tests. Moreover, successive tests were separated by a 48-h between-tests interval, during which the animals were submitted daily to a free exploration session of $5 \mathrm{~min}$ in normal (OFF) conditions. Thus, during the course of testing, the duration of the animals' exposure to the ON condition was about 30 times less than their total exposure to the normal conditions. The 39 animals were assigned to three groups according to retention interval 6, 48, and $72 \mathrm{~h}$. For each group, testing began and ended with two tests at the 5-min retention interval. Between these two tests, the animals were submitted to eight successive tests at the retention interval they were assigned to and with the OFF-OFF (four tests) and OFF-ON (four tests) conditions alternating.

\section{Results}

The results of Experiment 3 are summarized in Figure 4 . They show that providing normal mice with a change of the context during the retention test produced a slight, but not significant, improvement of spontaneous alternation rates at the 48-h retention interval [from $51.9 \%$ to $63.4 \% ; F(1,12)=2.51, p=.14]$. No effect was observed at 6 and $72 \mathrm{~h}[F(1,12)<0.81$ in both cases]. Mixed-designed ANOVAs with retention interval as the between-group factor and context as the withingroups factor showed a slight, but not significant, effect of the context change (from $59.8 \%$ to $65.4 \%$ across all

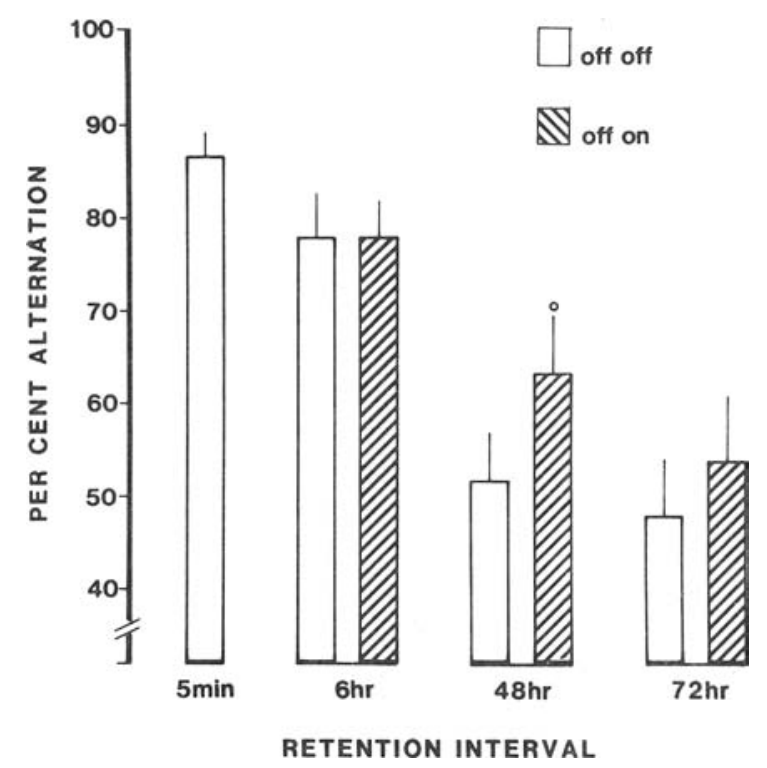

Figure 4. Percent alternation (mean $\pm S E M$ ) as a function of the retention interval and testing conditions (with cardboard added in retention, OFF-ON, and without, $\mathrm{OFF}-\mathrm{OFF}$ ) in control mice. ${ }^{\circ} p=.14$. 
three retention intervals $[F(1,36)=2.53, p=.12]$. Moreover, there was no significant context $\times$ retention interval interaction even in the most favorable case [i.e., 6 vs. $48 \mathrm{~h} ; F(1,24)=1.73, p=.20$ ]. Data analysis that included repetition as a factor (two first vs. two last exposures to the $\mathrm{ON}$ condition) showed a total lack of effect of this factor $(F<0.56$ for all interactions, whatever the retention interval).

\section{Discussion}

The present data seem to indicate that the context change (ON) might have a slight tendency to improve performance in control mice when the relative novelty of the unusual context is enhanced. However, even in this condition, the facilitative effect is weak and statistically nonsignificant, whatever the performance level in normal (OFF) conditions (i.e., the retention interval). In addition, our data fail to demonstrate any significant context $x$ retention interval interaction or any significant global changes in performance across testing.

\section{GENERAL DISCUSSION}

The results of these three experiments (see Figure 5) can be summarized as follows. First, lesioning of the MM results in an accelerated rate of decay of spontaneous alternation as a function of the interval elapsing between two forced trials used as an acquisition test and a free trial used as a retention test. Thus, the retention interval needed to produce chance-level performance is about eight times longer for control $(48 h)$ than for experimental $(6 h)$ subjects. The assumption that accelerated decay of spontaneous alternation as a function of time reflects accelerated rate of forgetting presupposes that this rate is normal for short retention intervals. This condition was obviously met, since, with the 5-min retention interval, the spontaneous alternation rates of the experimental groups were normal (82.2\%) as compared with those of the controls (83.3\%) (means of the three pooled experiments). Second, providing animals with a unusual intramaze context (context change), notably at the time of the retention test alone, dramatically improved performance in $\mathbf{M M}$ lesioned mice but not, or only very weakly, in control mice. In this particular condition of testing, MM-lesioned and control mice exhibited the same rate of forgetting (Figure 5B).

It seems to be well established that, in cats, rats, and monkeys, lesions of the MM impair performance in spatial tasks, notably spatial reversal learning (Aggleton \& Mishkin, 1985; Holmes, Butters, et al., 1983; Thompson, 1981) and spatial delayed alternation (Field, Rosenstock, Cameron King, \& Greene, 1978; Holmes, Jacobson, et al., 1983; Irle \& Markowitsch, 1982). Moreover, in some studies, this alternation deficit was found to increase when long delays were used (Beracochea \& Jaffard, 1987; Greene \& Naranjo, 1986; Holmes, Jacobson, et al., 1983). The latter finding and the results of the present study together indicate that the MM play a role in memory, although this role appears to be limited to the spatial domain (Aggleton \& Mishkin, 1985). However, in some respects, our results differ from the previous data. First, the retention intervals we used were much longer (hours) than those previously investigated (less than $1 \mathrm{~min}$ ). Second, and probably more importantly, our procedure did not involve any reinforcement. Consequently, one could argue that the spontaneous-alternation performance measures an automatic form of memory that could be more sensitive than other forms to MM lesions (i.e., intentional or effortful memories). Although additional experiments are required to evaluate the importance of this factor, at least two nonexclusive hypotheses can account for the ab-
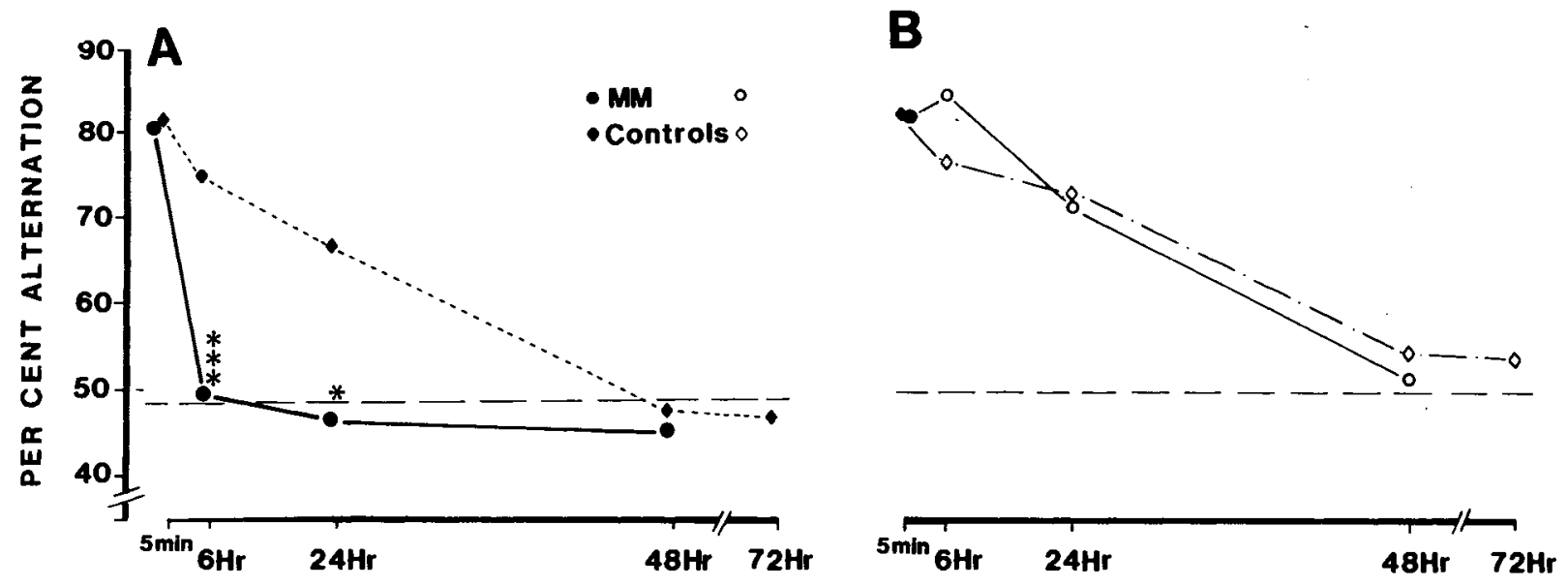

RETENTION INTERVAL

Figure 5. Pooled data of the three experiments. Mean percent alternation as a function of the retention interval in MM-lesioned and control groups (A) in normal conditions of testing (OFF) and (B) with a context change between acquisition and retention (OFF-ON) (open symbols). Significantly different from the control group: $* * * p<.001, * p=.024$. 
normal rate of forgetting following MM lesions. First, the lesion would weaken initial encoding of the memorial representation, thus leading to a more rapid dissipation of the memory trace. Second, experimental animals would have a normal memory trace (i.e., normal encoding and storage processes) but would suffer from a retrieval deficit.

The strongest evidence for an encoding deficit is the facilitative effect of the context change that, in subsequent 6-h retention test performance, occurred on the acquisition trial alone (ON-OFF procedure; Experiment 1). Indeed, one can suppose that the deficit was alleviated because attention was fully engaged by the unusual context. A second possibility, however, must be considered. Because of the high familiarity of the places (material) the animal had to remember, it seems reasonable to assume that temporal (recency), rather than recognition, memory underlay its performance. In these conditions, a loss of temporal discrimination control could account for the deficits, since episodes (acquisition trials) that have been attached to the unusual context could serve as a temporal marker, thus leading to normal remembering. Such a hypothesis has been suggested to explain that, relative to their normal recognition performance, certain amnesics (and experimental animals) exhibit disproportional impairment with temporal order and/or proactive interference paradigms (Beracochea, Lescaudron, Tako, Verna, \& Jaffard, 1987; Huppert \& Piercy, 1976; Witt \& GoldmanRakic, 1983), which can be improved by contextual cuing (Winocur et al., 1981). Finally, although one cannot exclude the possibility that MM lesions result in a weakening of encoding processes in the broad sense, it seems clear that this hypothesis cannot account for all our present data. Indeed, information given in the usual context (OFF) was either retrieved or not, depending only on whether the new context was (ON) or was not (OFF) provided on the retention-test trial. This strongly suggests that the deficit observed in normal conditions would also stem from a basic failure in retrieval. The classical scheme of memory processes postulates that recognition performance depends both on the memory trace and on the recovery of information from this trace (retrieval); furthermore, one can suppose that, as the retention interval increases, retrieval mechanisms have to be activated more and more in order to compensate for the time-dependent dissipation of the memory trace. In these conditions, even with a normal memory trace, the retention interval at which MM-lesioned subjects would no longer be able to spontaneously reach a sufficient level of activation would occur earlier in MM-lesioned than in control mice, thus explaining their accelerated rate of "forgetting." This retrieval-deficit hypothesis can also be drawn from such experiments as Tako's (1986), which showed that during the acquisition of a reference memory task in a radial maze with daily sessions of six trials, MM-lesioned mice were dramatically impaired on Trial 1 each day, but performed quite normally on Trials 2 to 6 . More generally, it has been suggested that a failure to spontaneously sustain the searching operations (lack of drive) involved in normal remembering could account for the amnesic Korsakoff syndrome (Meissner, 1968; see also Weingartner, 1984). Accordingly, we suggest that, for MM-lesioned mice, changing the context at the time of retrieval stimulates such searching operations, leading to normal remembering of the last twice-visited arm. The lack of a facilitative effect of this change in normal subjects would indicate that they can spontaneously reach an optimal level for processes aimed at recovering information. It must be noted that if both of the hypothesized processes subserving recognition performance (i.e., memory trace strength and retrieval) had been impaired, the only way to explain the total (not partial) alleviation of the deficit in experimental animals would be that the ON condition leads to more efficient (not equal) access to the memorial representation in them than in controls. Finally, it can be argued that a pure retrieval hypothesis does not account for the facilitation observed in the ON-OFF condition. Note, however, that, in this case, the animal apparently perceived the change in the acquisition (twice $O N$ ) versus retention (OFF) context, even though the lack of an increase in retention choice latencies (Table 1) is not in agreement with this perception of change proposal.

Taken as a whole, the presently observed deficits could be described mainly as "forgetting to remember," which could be secondary to a failure of attention, as suggested by the dramatic facilitative effect of the context change. Accordingly, there is no reason to suppose that such an attention deficit does not influence initial acquisition. It remains possible, however, that the two-forced-trial acquisition procedure improved the degree to which the mice attended to the relevant stimuli, and thereby tended to minimize, by means of a ceiling effect, the presumed between-groups difference. In any case, the present data, together with previously obtained data showing an impairment of spontaneous alternation specific to sequential test procedures (Beracochea \& Jaffard, 1987), are reminiscent of those reported for frontal lobe pathologies (see Schacter, 1987). More precisely, it has been suggested that some selective memory disorders in Korsakoff patients (i.e., memory for spatiotemporal context, sensitivity to proactive interference) might be considered as consequences of frontal lobe dysfunction rather than the result of a weak memory (amnesia) (Squire, 1982). Now it must be noted that alcohol consumption in mice was found to produce the same impairments as those we have reported after MM lesions; furthermore, here, too, a context change was found to completely alleviate these deficits (Beracochea \& Jaffard, 1987; Beracochea, Lescaudron, Tako, et al., 1987; Jaffard, Beracochea, \& Tako, 1987). Finally, since, as for Korsakoff patients (Victor et al., 1971), alcohol consumption in mice results in a pronounced neuronal loss in the MM (Lescaudron et al., 1984), it is possible that damage to this structure contributes to those selective memory disorders generally considered as reflecting frontal lobe dysfunction.

In summary, it seems reasonable to suggest that, with respect to the nature of the task we have used, the observed patterns of spatial memory performance in MM- 
lesioned mice reflect mainly a failure that occurs at the time of retrieval. This, however, does not explain all pathologies that lead to a rapid dissipation of spontaneous alternation. When tested in normal conditions (OFF-OFF), the forgetting curve exhibited by senescent mice is quite similar to that exhibited by adult MMlesioned or alcohol-treated animals. However, only the performance of aged mice is unaltered under the OFF-ON condition (Jaffard et al., 1987). Although this finding does not prove that aging impairs the maintenance of the memory trace ("pure"' amnesia), such a comparison emphasizes the specificity of the deficit induced by MM lesions and provides new experimental evidence for different forms of memory dysfunction.

\section{REFERENCES}

Aggleton, J. P., \& Mishkin, M. (1985). Mammillary-body lesions and visual recognition in monkeys. Experimental Brain Research, 58, 190-197.

Beracochea, D. J., Durkin, T. P., \& JafFard, R. (1986). On the involvement of the central cholinergic system in memory deficits induced by long-term ethanol consumption in mice. Pharmacology, Biochemistry \& Behavior, 24, 519-524.

Beracochea, D. J., \& JaFFARD, R. (1985). Memory deficits subsequent to chronic consumption of alcohol in mice: An analysis based on spontaneous alternation behavior. Behavioral Brain Research, 15, 15-25.

BERACOCHEA, D. J., \& JAFFARD, R. (1987). Impairment of spontaneous alternation behavior in sequential test procedures following mammillary bodies lesions in mice. Evidence for time-dependent interference related memory deficits. Behavioral Neuroscience, 101, 187-197.

Beracochea, D. J., Lescaudron, L., Tako, A. N., Verna, A., \& JAFFARD, R. (1987). Build-up and release from proactive interference during chronic ethanol consumption in mice: $A$ behavioral and neuroanatomical study. Behavioral Brain Research, 25, 63-74.

Beracochea, D. J., Lescaudron, L., Verna, A., \& Jaffard, R. (1987). Neuroanatomical effects of chronic ethanol consumption on dorsomedial and anterior thalamic nuclei and on substantia innominata in mice. Neuroscience Letters, 83, 81-84.

BrIERLY, J. B. (1977). Neuropathology of amnesic states. In C. W. M. Whitty \& O. L. Zanfwill (Eds.), Amnesia (pp. 199-223). London: Butterworths.

Field, T. D., Rosenstock, J., Cameron King, E., \& Greene, E. (1978). Behavioral role of the mammillary efferent system. Brain Research Bulletin, 3, 451-456.

Greene, E., \& NARANJo, J. N. (1986). Thalamic role in spatial memory. Behavioral Brain Research, 19, 123-131.

Holmes, E. J., Butters, N., JAcobson, S., \& Stein, B. M. (1983). An examination of the effects of mammillary-body lesions on reversal learning sets in monkeys. Physiological Psychology, 11, 159-165.

Holmes, E. J., Jacobson, S., Stein, B. M., \& Butters, N. (1983). Ablation of the mammillary nuclei in monkeys: Effects on postoperative memory. Experimental Neurology, 81, 97-113.

Holmes, E. J., \& SCHROEDER, C. E. (1986). Object recognition memory following diencephalic lesions in monkeys. Society for Neuroscience Abstracts, 12, 976.
HupPert, F. A., \& Piercy, M. (1976). Recognition memory in amnesic patients: Temporal context and familiarity of material. Cortex, 12, 3-20.

IRLE, E., \& MARKOWITSCH, H. S. (1982). Single and combined lesions of the cat's thalamic mediodorsal nucleus and the mammillary bodies lead to severe deficits in the acquisition of an alternation task. $B e$ havioral Brain Research, 6, 147-165.

JAFFARD, R., Beracochea, D. J., \& TAKo, A. N. (1987). Accelerated rate of forgetting of spatial information with aging and long-term ethanol consumption in mice: Evidence for two forms of amnesia. Society for Neuroscience Abstracts, 13, 1126.

Lehmann, A. (1974). Atlas stéréotaxique du cerveau de souris (Editions due Centre National de la Recherche Scientifique). XXXXXXX: CNRS.

Lescaudron, L., Beracochea, D., Verna, A., \& JAFFARD, R. (1984). Chronic ethanol consumption induces neuronal loss in mammillary bodies of the mouse: A quantitative analysis. Neuroscience Letters, 50, 151-155.

Lescaudron, L., \& Verna, A. (1985). Effects of chronic ethanol consumption on pyramidal neurons of the mouse dorsal and ventral hippocampus: A quantitative histological analysis. Experimental Brain Research, 58, 362-367.

MAYes, A. R., \& MeUdell, P. R. (1984). Problems and prospects for research on amnesia. In L. R. Squire \& N. Butters (Eds.), Neuropsychology of memory (pp. 134-144). New York: Guilford Press.

McEntee, W. J., Biber, M. P., Perl, D. P., \& Benson, D. F. (1976). Diencephalic amnesia: A reappraisal. Joumal of Neurology, Neurosurgery \& Psychiatry, 39, 436-441.

Meissner, W. W. (1968). Learning and memory in the Korsakoff syndrome. Joumal of Neuropsychiatry, 4, 6-20.

SAUNDERS, R. C. (1983). Impairment in recognition memory after mammillary body lesions in monkeys. Society for Neuroscience Abstracts, 9, 28.

SCHACTER, D. L. (1987). Memory, amnesia and frontal lobe dysfunction. Psychobiology, 15, 21-36.

SQUIRE, L. R. (1982). The neuropsychology of human memory. Annual Review of Neuroscience, 5, 241-273.

Tако, A. N. (1986)Etude neuropsychologique des amnésies d'origine alcoolique et carentielle chez la souris. Thèse de Doctorat, Université de Bordeaux I.

THOMPSON, R. (1981). Rapid forgetting of spatial habit in rats with hippocampal lesions. Science, 212, 959-960.

Victor, M., AdAMs, R. D., \& Collins, G. H. (1971). The WernickeKorsakoff syndrome. Philadelphia: Davis.

WEINGARTNER, H. (1984). Psychobiological determinants of memory failures. In L. R. Squire \& N. Butters (Eds.), Neuropsychology of memory (pp. 203-212). New York: Guilford Press.

Winocur, G., \& KinsBourne, M. (1978). Contextual cuing as an aid to Korsakoff amnesics. Neuropsychologia, 16, 671-682.

Winocur, G., KinsBourne, M., \& Moscovitch, M. (1981). The effect of cuing on release from proactive interference in Korsakoff amnesic patients. Joumal of Experimental Psychology: Human Learning \& Memory, 7, 56-65.

WitT, E. D., \& Goldman-Rakıc, P. S. (1983). Intermittent thiamine deficiency in the rhesus monkey: II. Evidence for memory loss. Annals of Neurology, 13, 396-401.

(Manuscript received April 23, 1987; revision accepted for publication January $31,1988$. 